\title{
Comorbidities in the management of patients with lung cancer
}

\author{
Charlotte Leduc ${ }^{1}$, Delphine Antoni ${ }^{2}$, Anne Charloux ${ }^{3}$, Pierre-Emmanuel Falcoz ${ }^{4}$ \\ and Elisabeth Quoix ${ }^{1}$
}

Number 3 in the series "Multidisciplinary questions in thoracic oncology: the team experience"

Edited by J.P. Sculier

\begin{abstract}
Affiliations: ${ }^{1}$ Pneumology Dept, Nouvel Hôpital Civil, Strasbourg Cedex, France. ${ }^{2}$ Radiotherapy Dept, Centre Paul Strauss, Strasbourg Cedex, France. ${ }^{3}$ Physiology and Functional Explorations Dept, Strasbourg Cedex, France. ${ }^{4}$ Thoracic Surgery Dept, Nouvel Hôpital Civil, Strasbourg Cedex, France.

Correspondence: Elisabeth Quoix, Pneumology Dept, Nouvel Hôpital Civil, 1, Place de l'Hôpital, 67091 Strasbourg Cedex, France. E-mail: Elisabeth.quoixdachru-strasbourg.fr
\end{abstract}

@ERSpublications

Comorbidities are frequent in patients with lung cancer and impact on their diagnostic and therapeutic management http://ow.ly/7ixJ307cpbL

Cite this article as: Leduc C, Antoni D, Charloux A, et al. Comorbidities in the management of patients with lung cancer. Eur Respir J 2017; 49: 1601721 [https://doi.org/10.1183/13993003.01721-2016].

ABSTRACT Lung cancer represents a major public health issue worldwide. Unfortunately, more than half of them are diagnosed at an advanced stage. Moreover, even if diagnosed early, diagnosis procedures and treatment can be difficult due to the frequent comorbidities observed in these patients. Some of these comorbidities have a common major risk factor, i.e. smoking, whereas others are unrelated to smoking but frequently observed in the general population. These comorbidities must be carefully assessed before any diagnostic and/or therapeutic decisions are made regarding the lung cancer. For example, in a patient with severe emphysema or with diffuse lung fibrosis, transthoracic needle biopsy can be contraindicated, meaning that in some instances a precise diagnosis cannot be obtained; in a patient with chronic obstructive pulmonary disease, surgery may be impossible or should be preceded by intensive rehabilitation; patients with interstitial lung disease are at risk of radiation pneumonitis and should not receive drugs which can worsen the respiratory insufficiency. Patients who belong to what are called "special populations", e.g. elderly or HIV infected, should be treated specifically, especially regarding systemic treatment. Last but not least, psychosocial factors are of great importance and can vary from one country to another according to health insurance coverage.

Received: Aug 302016 | Accepted after revision: Nov 252016

Previous articles in this series: No. 1: Malhotra J, Malvezzi M, Negri E, et al. Risk factors for lung cancer worldwide. Eur Respir J 2016; 48: 889-902. No. 2: McDonald F, De Waele M, Hendriks LEL, et al. Management of stage I and II nonsmall cell lung cancer. Eur Respir J 2017; 49: 1600764.

Conflict of interest: None declared.

Copyright @ERS 2017 


\section{Introduction}

Lung cancer is the most frequent cause of death by cancer worldwide. Most lung cancers are diagnosed at an advanced stage, either locally or metastatic. Surgery is the main treatment for early-stage disease whereas concurrent chemotherapy and radiation therapy must be considered for locally advanced disease and chemotherapy for stage IV disease (or targeted therapies in case of EGFR mutations, V600E BRAF mutation, and $A L K$ or ROS1 translocation).

With lung cancer being far more frequent in smokers and ex-smokers, these patients often have tobacco-related illnesses, mainly cardiovascular (ischaemic or hypertensive heart disease, lower limbs arteriopathy, etc.) and respiratory (chronic obstructive pulmonary disease (COPD), obstructive sleep apnoea, usual interstitial fibrosis. etc.) in nature. They can also have other comorbidities that are unrelated to tobacco use but that are frequent in the general population, e.g. diabetes and its complications (renal insufficiency, cardiovascular damage). These comorbidities can alter the performance status of the patients often more than the tumour development. Lung cancer is also more frequent in elderly patients because ageing is by itself a risk factor for the development of lung cancer. Of course, comorbidities are more frequent with ageing and more severe independent of the physiological alterations inherent to ageing. All these comorbidities can have deleterious effects on the diagnostic procedures and, moreover, on the treatment possibilities and thus must be carefully explored.

\section{Epidemiology}

\section{Respiratory diseases}

Chronic obstructive pulmonary disease and emphysema

COPD is the fourth leading cause of death worldwide. COPD and lung cancer are closely related, first because they share the same main risk factor, smoking exposure, which is found in $85-90 \%$ of those diagnosed with either COPD or lung cancer. However, COPD is also an independent risk factor for lung cancer, taking into account sex, age and smoking history. Smokers with COPD are five times more likely to develop lung cancer than smokers without COPD $[1,2]$. The risk of developing lung cancer is correlated with the lung function measure forced expiratory volume in $1 \mathrm{~s} \mathrm{(FEV1)} \mathrm{and} \mathrm{with} \mathrm{female} \mathrm{sex} \mathrm{[3].}$ Emphysema, which is frequently associated with COPD, also increases the risk of lung cancer [4]. Coexisting COPD is associated with worse survival outcomes after surgery in patients with early-stage (IA and IB) nonsmall cell lung cancer (NSCLC), especially in men and in squamous-cell carcinomas (5-year overall survival, $54.4 \%$ with COPD versus $69.0 \%$ without, $\mathrm{p}=0.0002$ ) [5]. The association between COPD and lung cancer is explained by several mechanisms. Oxidative damage [6] and chronic inflammation enhance oncogenesis involving inflammatory mediators and DNA repair [7, 8]. Moreover, the irreversible airflow obstruction that characterises COPD can lead to airborne carcinogen retention. Genetic and epigenetic factors (CHRNA3/5, HHIP, TERT, DNA hypermethylation, miRNAs, etc.) might also be implicated in both lung cancer and COPD [9-11].

\section{Bronchiectasis}

Bronchiectasis is a chronic respiratory disease characterised by irreversible airway dilatation. It is caused by chronic inflammation and infections resulting in the destruction of the bronchial walls, and is associated with systemic inflammation [12]. Mechanisms that explain the relationship between lung cancer and bronchiectasis are poorly known. In the same way as in COPD, chronic inflammation leads to carcinogenesis. About $20 \%$ of cancers worldwide are caused by infections [13], thus recurrent microbial infections in bronchiectasis could favour lung cancer development [14]. Bronchiectasis has been shown as an independent risk factor of lung cancer in a large Asian population-based cohort $(n=53755$, hazard ratio (HR) 2.36, 95\% CI 2.19-2.55) [15].

\section{Tuberculosis}

Tuberculosis (TB) is a major cause of morbidity and mortality, especially in developing countries, with 9.6 million new cases and 1.5 million deaths annually worldwide [16]. In 2005, 426457 cases of TB were reported in the World Health Organization (WHO) European region [17]. TB causes lung inflammation and fibrosis, and can increase the risk of lung cancer [18-22]. Numerous studies have demonstrated that $\mathrm{TB}$ increases the risk of developing lung cancer independently of smoking or environmental tobacco smoke exposure, with a relative risk (RR) of 1.8 in never-smoking patients (95\% CI 1.4-2.2) [23]. The risk seems to be higher in the 5 years following TB infection $[23,24]$. Interestingly, the association has proved significant with adenocarcinoma (RR 1.6, 95\% CI 1.2-2.1), but not with other histologies [23]. Moreover, a history of pulmonary $\mathrm{TB}$ has been described as an independent, unfavourable prognostic factor for lung cancer survival in a prospective population-based Dutch cohort (HR 2.36, 95\% CI 1.1-4.9) [25]. 
Interstitial lung diseases

Different studies suggest a link between interstitial lung diseases (ILDs) and lung cancer, through different pathogenetic mechanisms, including chronic inflammation and epithelial mesenchymal transition [26, 27]. Several recent studies have shown that the incidence of lung cancer is increased in patients with idiopathic pulmonary fibrosis, independently of smoking status, with an adjusted RR between 1.51 (95\% CI 1.20-1.90, $\mathrm{p}<0.001)$ and 8.25 (95\% CI 4.70-11.48, p<0.001) [28-30]. Moreover, idiopathic pulmonary fibrosis has been described as an independent risk factor for postoperative mortality and poor long-term survival, especially in patients with stage I/II NSCLC [31]. In patients with underlying ILD, lung cancers are mostly squamous-cell carcinomas and located at the periphery of the lung [32, 33]. ILD associated with systemic sclerosis is also associated with a higher risk of lung cancer, which can be due to the cellular injury caused by inflammation and fibrosis but also to the immunosuppressive therapy often used in this disease [34].

Diseases that promote the occurrence of lung cancer all have in common, besides tobacco exposure at least in COPD, the fact that they are accompanied by chronic inflammation, which increases the effects of exposure to other carcinogens. These diseases also impact the diagnosis and, more so, the treatment of these patients, and they often confer a worse prognosis.

\section{Cardiovascular diseases}

Cardiovascular diseases (CVDs) are observed in $23 \%$ of patients with lung cancer [35]. They can impact on survival and limit therapeutic options [36]. This high prevalence can be explained by several factors. First, the two pathologies share common main risk factors, i.e. smoking and age. Both COPD and CVD are associated with chronic inflammation, which could also explain the association between the two pathologies $[37,38]$. In a recent Norwegian study, self-reported CVD was shown as an independent risk factor for the development of lung cancer in former smokers (HR 1.74, 95\% CI 1.11-2.73) and current smokers (HR 1.38 95\% CI 1.04-1.83) [39]. Most CVDs were associated with decreased survival in NSCLC patients, especially for stage I-IIIB patients. Heart failure, myocardial infarction and cardiac arrhythmias were associated with the worst prognoses, whereas hyperlipidaemia at baseline was associated with a better prognosis [40]. CVDs are also associated with an increased mortality related to treatments [40], and represent the most important cause of non-cancer death, especially for patients aged $>60$ years at diagnosis [41]. For all these reasons, management of CVD is important in lung cancer patients.

\section{Other diseases}

Human immunodeficiency virus and acquired immune deficiency syndrome

Today, 33.3 million people live with HIV infection worldwide. HIV infection increases the risk of cancer, which is becoming the leading cause of death in HIV-infected (HIV+) patients (22\% in 2010 versus $11 \%$ in 2000), especially lung cancer (60\% of cases) [42,43]. The estimated incidence of cancer among HIV+ patients was 14 per 1000 person-years in 2006 in the French study ONCOVIH [44]. HIV+ lung cancer patients are younger than HIV-negative (HIV-) patients and present with more advanced disease. It has been reported that HIV+ patients are undertreated for lung cancer [45]. HIV is also associated with higher lung cancer-specific mortality. The increased risk of lung cancer in HIV+ patients is multifactorial: HIV+ patients are often heavy smokers (tobacco and cannabis) [46], but the risk remains higher after adjusting for tobacco. Immunodeficiency, especially CD4 lymphocyte cell count, seems to be an important predictive risk factor for malignancies in HIV (RR 2.2, 95\% CI 1.3-3.6 to RR 8.5, 95\% CI 4.3-16.7 for lung cancer, $\mathrm{p}<0.0001$ ) [42]. Finally, HIV+ patients' lungs are weakened by various diseases, such as COPD, emphysema, bronchiectasis, ILD, pneumocystis or other infections, which also contributes to the risk of developing lung cancer [43]. Several prognostic factors have been identified, some of them common to all lung cancers, including performance status and TNM stage, and some of them specific to HIV infection, including CD4 count and highly active antiretroviral therapy (HAART) [47, 48]. However, the survival of HIV+ patients increased considerably with the advent of HAART and, thus, these patients are now reported to develop cancers that are related in part to ageing, such as lung cancer. In addition, the prognosis of HIV+ patients with lung cancer, which was quite sobering in the pre-HAART era, is now similar to HIV- patients [49].

Hepatitis $B$ and $C$ virus

Infections with hepatitis B virus (HBV) or hepatitis C virus (HCV) are associated with significant morbidity and mortality among patients with cancer, especially in patients with haematologic malignancies. HBV infection seems to be associated with poor prognosis in patients with advanced NSCLC [50]. HBV reactivation, defined by the development of hepatitis in association with an increase in serum HBV DNA level, is a well-known complication in patients with cancer undergoing cytotoxic chemotherapy and can be lethal [51,52]. The risk correlates with the HBV infection status prior to chemotherapy and with the degree of immunosuppression due to chemotherapy. The chemotherapeutic 
regimens for NSCLC are less intensive than those used for haematologic malignancies, but a study has reported HBV reactivation for nearly $20 \%$ of hepatitis B surface antigen (HBsAg)-positive NSCLC patients without antiviral prophylaxis [53]. HBV reactivation has also been described after the withdrawal of erlotinib in cases of EGFR mutation [54]. Consequently, it is important to screen for $\mathrm{HBsAg}$ and anti-hepatitis $\mathrm{B}$ core antigen in patients at a high risk for HBV infection (i.e. patients coming from high HBV-endemic regions, with a history of intravenous drug abuse, undergoing haemodialysis or who are HIV-positive, and homosexual men) before starting treatment. In cases of a high risk of reactivation, prophylactic lamivudine significantly reduced the prevalence of $\mathrm{HBV}$ reactivation in patients with haematologic malignancies and in patients with solid tumours $[55,56]$.

HCV infection is more common than HBV infection in patients with cancer [57]. Its role in hepatocellular carcinoma is well known, and its prevalence is reported to be higher in haematological cancers but not in lung cancer [58,59]. HCV reactivation is described in haematologic malignancies [60], particularly in solid tumours $[61,62]$. There is no specific attention to pay regarding lung cancer treatment, except to closely monitor alanine transaminase (ALT) and HCV viral load levels during and after chemotherapy.

\section{Renal insufficiency}

Chronic renal insufficiency is characterised by a glomerular filtration rate $<60 \mathrm{~mL} \cdot \mathrm{min}^{-1} \cdot 1.73 \mathrm{~m}^{-2}$ for more than 3 months. The Modification of Diet in Renal Disease method is recommended for the routine calculation of glomerular filtration rate in patients with cancer [63]. Renal function declines with age owing to renal mass shrinking, a reduction in renal blood flow and gradual loss of functioning nephrons [64]. Chronic renal disease is common in patients with lung cancer, even more so as $30 \%$ of patients with lung cancer are elderly [65], and it has an impact on survival in both early-stage and advanced lung cancer [66] and on the treatment: use of carboplatin rather than cisplatin, avoiding use of gemcitabine or pemetrexed etc.

\section{Diabetes mellitus}

Diabetes mellitus is one of the major public health problems worldwide and is associated with immunosuppression and vascular complications [67]. Approximately $8-18 \%$ of patients with cancer also have diabetes. Lung cancer and diabetes mellitus share common risk factors, explaining the association between these two diseases, such as age, diet and smoking. Hyperglycaemia has also been implicated in carcinogenesis, although its role is controversial. It is known that hyperinsulinaemia enhances the synthesis of insulin-like growth factor 1 (IGF-1), and that the binding of IGF-1 to its ligand IGF-1R activates the PI3K/AKT/mTOR pathway, which is implicated in carcinogenesis. Overproduction of reactive oxygen species could also increase the risk of cancer in diabetic patients: reactive oxygen species can damage DNA, contributing to mutagenesis and carcinogenesis [68]. The latest hypothesis is that the abundance of inflammatory cells in adipose tissue of diabetic patients could promote systemic inflammation and thus carcinogenesis [69]. Diabetes mellitus is associated with higher mortality in patients with lung cancer, increasing the risk of cardiovascular events, postoperative complications and susceptibility to infection [70-72].

\section{Impact of comorbidities on lung cancer surgery}

Comorbidity is associated with increased perioperative mortality. In a national prospective study by the French Society of Thoracic and Cardio-Vascular Surgery that included $>15000$ patients, those with at least three comorbidities had approximately 2.5 times the risk of in-hospital death of patients with no comorbidity [73]. Smoking addiction, history of cancer, COPD, arterial hypertension and heart disease accounted for $70 \%$ of these comorbidities. In another series of $\sim 11000$ surgical patients, a significant association was observed between the Charlson index and postoperative death within 90 days (the adjusted odds ratio for a Charlson index of 2-3 was 1.54) [74].

Because of lung cancer progression, surgery cannot be delayed beyond a few weeks. This short period should, however, be used to optimise the patient's condition. Before surgery, therapeutic optimisation of respiratory, cardiac and renal diseases; diabetes mellitus; and nutritional status is mandatory. Screening for obstructive sleep apnoea syndrome, often undiagnosed, should be included in the preoperative assessment [75]. Despite the limited amount of data currently published, smoking cessation, physical therapy and pulmonary rehabilitation should be offered to reduce perioperative risks and long-term pulmonary disability [76, 77]. A recent French Epithor database analysis showed that underweight patients are at high risk of perioperative complications: in addition to preoperative rehabilitation including a nutritional programme, attention should be given to aggressive prophylactic respiratory therapy in the perioperative period (pre- and immediately after surgery) [78]. If perioperative management of cardiac diseases is well standardised, fewer recommendations have been proposed regarding cerebrovascular disease. Perioperative stroke is a rare complication $(0.1 \%)$ [79] but characterised by a high perioperative mortality. To reduce the risk of perioperative stroke, antiplatelet/anticoagulant treatments should be continued whenever possible 
throughout the perioperative period. In patients with transient ischaemic attack or stroke in the preceding 6 months, carotid revascularization should be performed before lung surgery [80].

A functional assessment performed either initially or following therapeutic optimisation can demonstrate persistent high perioperative risk. The two most frequent situations leading to the consideration of other therapeutic options are lung function alteration and heart failure. Perioperative morbidity and mortality as well as long-term functional disability resulting from lung resection depend on the extent of resection as well as the patient's preoperative lung function. Calculating the predicted postoperative FEV1, the diffusing capacity of the lung for carbon monoxide (DLCO) or maximal oxygen uptake $\left(V^{\prime} \mathrm{O}_{2} \max \right)$ have proved valuable in evaluating the pulmonary reserve of the patient. Patients with a predicted postoperative FEV 1 or predicted postoperative DLCO $<40 \%[81]$ or $30 \%[82,83]$ before "major" resection have been identified as being at increased perioperative risk. $\mathrm{A} V^{\prime} \mathrm{O}_{2} \max <10 \mathrm{~mL} \cdot \mathrm{kg}^{-1} \cdot \mathrm{min}^{-1}$ or $<35 \%$ of predicted indicates a high risk for perioperative death [82,83] or cardiopulmonary complications [81] if a major anatomic lung resection through thoracotomy is considered. Minimally invasive surgery and sub-lobar resections or non-surgical treatment options should then be discussed. It is worth noting, however, that lower lung function limits for sub-lobar resections remain to be defined.

Heart failure is a well-recognised factor for perioperative cardiac complications. In a large study of $>159000$ non-cardiac procedures, overall mortality among patients with heart failure was $8.0 \%$, more than triple the mortality in patients with neither coronary artery disease nor heart failure [84]. There is no defined lower limit of left ventricle ejection fraction (LVEF) for thoracic surgery, but a reduced LVEF of $\leqslant 35 \%$ was found to be a strong predictor of postoperative cardiac events following vascular surgery [85]. In another study, a LVEF of $<30 \%$ was associated with increased rates of perioperative events compared with moderately reduced (LVEF 30-40\%) or mildly reduced (LVEF 40-50\%) left ventricle function [86]. It is recommended that patients with established or newly diagnosed heart failure who are scheduled for intermediate or high-risk non-cardiac surgery be therapeutically optimised. However, it can be necessary to allow at least 3 months after the initiation of heart failure to allow for therapy up-titration and possible improvement of left ventricular function [87]. Such a delay can be incompatible with carcinological imperatives.

\section{Impact of comorbidities on lung cancer radiotherapy}

Radiation therapy improves locoregional control and survival in patients diagnosed with NSCLC and small-cell lung cancer. The most frequently used treatment is three-dimensional conformal radiation therapy combined or not with chemotherapy or surgery. Stereotactic radiotherapy is an alternative to surgery for stage T1T2A lung cancer without involved nodes for patients who refuse or are not eligible for surgery. Irradiation of mediastinal tumours can induce radiation pneumonitis (RP). The total dose, fractionation schedule, irradiated lung volume and dosimetric factors are all related to the development of RP [88-90]. Concurrent or sequential chemotherapy has been shown to increase the risk of RP in some studies [91-95], but not in others [96-100]. Some patient-specific risk factors can influence the rate of symptomatic RP. CLAUDE et al. found that age can increase the risk of RP [99]. In a prospective study of 96 patients who received three-dimensional conformal radiation therapy for stage IA-IIIB NSCLC, 40 patients $(44 \%)$ had RP (grade $\geqslant 1$ ) at 6 weeks, including 7 patients $(7.8 \%)$ with severe RP (grade $\geqslant 2$ ). An age $>60$ years was also significantly related with RP; however, this was not confirmed in other studies [91, 98, 101, 102]. A low Karnofsky performance status has been found to increase the risk of RP in one study [97], but not in others $[91,99]$. There is also conflicting evidence regarding whether tumour location influences the risk of RP $[92,97,102]$. Monson et al. showed that the development of RP was significantly more common among patients with a smoking history than among those who never smoked [96]. Smoking seems to have a paradoxical role in RP: smoking history could increase the risk of RP as a result of pre-existing lung damage, but active smoking somehow protects the lungs from radiotherapy-induced damage. YAMAGUCHI et al. performed a retrospective analysis of 62 patients receiving thoracic radiotherapy and evaluated the association between subclinical ILD and fatal RP [103]. Eleven patients had an untreated and asymptomatic ILD and grade 2-5 RP was observed in 4 of these 11 patients. Subclinical ILD has been observed to significantly influence the development of grade 2-5 RP ( $\mathrm{p}=0.0274)$ [104], with a significant trend for grade $5(\mathrm{p}=0.0785)$. Several patient-specific factors, including age, smoking history, tumour location, performance score, sex and treatments (chemotherapy regimen and schedule), have been proposed as potential predictors of RP, but these have not been consistently demonstrated across different studies.

\section{Impact of comorbidities on the use of systemic treatment}

Specific data concerning dose adaptation of systemic therapies (chemotherapies and targeted therapies) according to comorbidities are seldom seen in the literature, except with regards renal and hepatic failure. A review of medical cancer treatment of lung cancer associated with comorbidities has recently been published [105], emphasising the need for a better appraisal of the impact of comorbidities. 


\section{Chemotherapy}

Cisplatin requires good hydration and consequently should not be used in patients with pre-existing reduced LVEF or who are at risk of pulmonary oedema. Anthracyclines are the best known of the chemotherapeutic agents that cause cardiotoxicity and are contraindicated in cases of reduced LVEF. Other agents such as etoposide or vinorelbine have also been occasionally associated with cardiotoxicity, and should be used with caution [106]. Regarding patients with chronic renal insufficiency, recommendations from the International Society of Geriatric Oncology (SIOG) summarise the recommended dosage adjustment of anticancer drugs [107]. The majority of cancer therapies used in lung cancer do not require dose adaptations for a glomerular filtration rate between 60 and $90 \mathrm{~mL} \cdot \mathrm{min}^{-1}$. Cisplatin is not recommended when clearance is lower than $60 \mathrm{~mL} \cdot \mathrm{min}^{-1}$ and carboplatin use is preferable. Pemetrexed is contraindicated when clearance is $<45 \mathrm{~mL} \cdot \mathrm{min}^{-1}$. Dose adjustments for the main agents used in lung cancer are summarised in table 1. Some chemotherapies must also be adjusted to liver function, and those adjustments are summarised in table 2. Concerning patients on dialysis, there is no specific recommendation in the literature. Several case reports had shown that administration of chemotherapy is feasible before dialysis sessions [108].

Chemotherapy-related exacerbation of ILD has been reported in $8.7-21 \%$ of cases $[109,110]$, notably with mitomycin, gemcitabine and docetaxel $[111,112]$, and these drugs should not be used in patients with ILDs. Platin salts, vinorelbine and etoposide are considered to be safe in patients with advanced NSCLC and ILD [110, 113]. Generally speaking, clinicians must be aware of this occasional complication during chemotherapy and closely monitor their patients. Bronchoalveolar lavage with cellular analysis (lymphocytes, eosinophils, neutrophils) should be performed whenever there is any doubt and followed by corticosteroid treatment.

\section{Targeted therapy}

Tyrosine-kinase inhibitors (TKI), at least erlotinib, gefitinib and crizotinib, are well known to induce ILD, even if there is no pre-existing fibrosis [114]. However, with regards patients with concurrent EGFR mutation and $A L K$ translocation, TKI may not be systematically contraindicated in patients with pre-existing fibrosis; clinicians should decide on a case-by-case basis, considering patients' characteristics and other comorbidities [115]. TKI should also be given with dose adaptation in patients with renal failure $[116,117]$ or hepatic failure, but specific studies are lacking (tables 1 and 2).

TABLE 1 Dose adjustments of lung cancer main chemotherapies in case of renal dysfunction

\begin{tabular}{|c|c|c|}
\hline Agent & Glomerular filtration rate $\mathrm{mL} \cdot \mathrm{min}^{-1}$ & Dosage \\
\hline \multirow[t]{2}{*}{ Carboplatin } & $>60$ & AUC5 or AUC6 every 3 weeks \\
\hline & $<60$ & Adjust using the Calvert or Chatelut formula \\
\hline \multirow[t]{2}{*}{ Cisplatin } & $>60$ & $75 \mathrm{mg} \cdot \mathrm{m}^{-2}$ every 3 weeks \\
\hline & $<60$ & Not recommended \\
\hline \multirow[t]{3}{*}{ Pemetrexed } & $>60$ & $500 \mathrm{mg} \cdot \mathrm{m}^{-2}$ every 3 weeks \\
\hline & $45-60$ & $500 \mathrm{mg} \cdot \mathrm{m}^{-2}$ every 3 weeks \\
\hline & $<45$ & Not recommended \\
\hline \multirow[t]{3}{*}{ Etoposide } & $>60$ & $100-120 \mathrm{mg} \cdot \mathrm{m}^{-2} \cdot \mathrm{dL}^{-3}$ every 3 weeks \\
\hline & $15-60$ & $75 \mathrm{mg} \cdot \mathrm{m}^{-2} \cdot \mathrm{dL}^{-3}$ every 3 weeks \\
\hline & $<15$ or haemodialysis & $50 \mathrm{mg} \cdot \mathrm{m}^{-2} \cdot \mathrm{dL}^{-3}$ every 3 weeks \\
\hline \multirow[t]{4}{*}{ Topotecan } & $>60$ & $1.5 \mathrm{mg} \cdot \mathrm{m}^{-2} \cdot \mathrm{dL}^{-3}$ every 3 weeks \\
\hline & $30-60$ & $1.5 \mathrm{mg} \cdot \mathrm{m}^{-2} \cdot \mathrm{dL}^{-3}$ every 3 weeks \\
\hline & $15-30$ & $0.75 \mathrm{mg} \cdot \mathrm{m}^{-2} \cdot \mathrm{dL}^{-3}$ every 3 weeks \\
\hline & $<20$ or haemodialysis & Not recommended \\
\hline \multirow[t]{3}{*}{ Gefitinib } & $>60$ & $250 \mathrm{mg} \cdot$ day $^{-1}$ \\
\hline & $20-60 \mathrm{~mL} \cdot \mathrm{min}^{-1}$ & $250 \mathrm{mg} \cdot \mathrm{day}^{-1}$ \\
\hline & $<20 \mathrm{~mL} \cdot \mathrm{min}^{-1}$ or haemodialysis & Not recommended \\
\hline \multirow[t]{3}{*}{ Erlotinib } & $>60 \mathrm{~mL} \cdot \mathrm{min}^{-1}$ & $150 \mathrm{mg} \cdot \mathrm{day}^{-1}$ \\
\hline & $15-60 \mathrm{~mL} \cdot \mathrm{min}^{-1}$ & $150 \mathrm{mg} \cdot \mathrm{day}^{-1}$ \\
\hline & $<15 \mathrm{~mL} \cdot \mathrm{min}^{-1}$ or haemodialysis & Not recommended \\
\hline \multirow[t]{3}{*}{ Crizotinib } & $>60$ & 250 mg twice daily \\
\hline & $30-60$ & 250 mg twice daily \\
\hline & $<30$ or haemodialysis & $250 \mathrm{mg} \cdot \mathrm{day}^{-1}$ \\
\hline \multirow[t]{3}{*}{ Afatinib } & $>60$ & $40 \mathrm{mg} \cdot \mathrm{day}^{-1}$ \\
\hline & $30-60$ & $40 \mathrm{mg} \cdot \mathrm{day}^{-1}$ \\
\hline & $<30$ or haemodialysis & Not recommended \\
\hline
\end{tabular}

AUC: area under curve. 


\begin{tabular}{|c|c|c|}
\hline Agent & Hepatic enzymes level & Dosage \\
\hline \multirow[t]{4}{*}{ Docetaxel } & Normal & $75 \mathrm{mg} \cdot \mathrm{m}^{-2}$ every 3 weeks \\
\hline & Bilirubin $>\mathrm{N}$ & Not recommended \\
\hline & AST-ALT $>1.5 \times N$ & Not recommended \\
\hline & $\mathrm{AP}>2.5 \times \mathrm{N}$ & Not recommended \\
\hline \multirow[t]{3}{*}{ Erlotinib } & Normal & $150 \mathrm{mg} \cdot \mathrm{day}^{-1}$ \\
\hline & AST-ALT $>3 \times N$ & $50 \%$ reduction \\
\hline & Bilirubin $>\mathrm{N}$ & $50 \%$ reduction \\
\hline \multirow[t]{3}{*}{ Etoposide } & Normal & $100-120 \mathrm{mg} \cdot \mathrm{m}^{-2}$ on $\mathrm{D} 1, \mathrm{D} 2$, D3 every 3 weeks \\
\hline & Bilirubin $>1.25-2.5 \times \mathrm{N}$ & $50 \%$ reduction \\
\hline & Bilirubin $>2.5 \times \mathrm{N}$ & Not recommended \\
\hline \multirow[t]{2}{*}{ Gemcitabine } & Normal & $1000-1250 \mathrm{mg} \cdot \mathrm{m}^{-2}$ \\
\hline & AST-ALT-bilirubin $>1-3 \times N$ & $800 \mathrm{mg} \cdot \mathrm{m}^{-2}$ \\
\hline \multirow[t]{3}{*}{ Irinotecan } & Normal & $350 \mathrm{mg} \cdot \mathrm{m}^{-2}$ every 3 weeks \\
\hline & Bilirubin $>1.5-3 \times \mathrm{N}$ & $200 \mathrm{mg} \cdot \mathrm{m}^{-2}$ every 3 weeks \\
\hline & Bilirubin $>3-5 \times N$ & Not recommended \\
\hline \multirow[t]{5}{*}{ Paclitaxel } & Normal & $175-200 \mathrm{mg} \cdot \mathrm{m}^{-2}$ every 3 weeks \\
\hline & AST-ALT >N & $135 \mathrm{mg} \cdot \mathrm{m}^{-2}$ every 3 weeks \\
\hline & Bilirubin $>1.25-2 \times N$ & $115 \mathrm{mg} \cdot \mathrm{m}^{-2}$ every 3 weeks \\
\hline & Bilirubin $>2-3.5 \times \mathrm{N}$ & $100 \mathrm{mg} \cdot \mathrm{m}^{-2}$ every 3 weeks \\
\hline & Bilirubin $>3.5 \times \mathrm{N}$ & Not recommended \\
\hline \multirow[t]{3}{*}{ Vinorelbine } & Normal & $25-30 \mathrm{mg} \cdot \mathrm{m}^{-2}$ per week \\
\hline & Bilirubin $>1.75-2.5 \times \mathrm{N}$ & $50 \%$ reduction \\
\hline & Bilirubin $>2.5 \times \mathrm{N}$ & $75 \%$ reduction \\
\hline
\end{tabular}

ALT: alanine aminotransferase; AST: aspartate aminotransferase; N: normal level.

\section{Immunotherapy}

Recently, the use of immune checkpoint inhibitors has generated considerable enthusiasm. Anti-programmed cell death protein 1 (PD1) drugs were first investigated with nivolumab as a second-line treatment of advanced NSCLC independent of programmed death-ligand 1 (PD-L1) expression by tumour cells $[118,119]$, or with pembrolizumab as a second-line [120] or first-line treatment in cases in which at least $50 \%$ of tumour cells expressed PD-L1 [121]. These drugs are either already approved or on the way to being approved, depending on the country. Anti-PD-L1 drugs are not yet approved but are at an advanced stage of clinical development, and include atezolizumab, durvalumab and avelumab. Treatment-related adverse events are quite different from those observed with chemotherapy and are generally speaking less severe. However, owing to the mechanism of action of these drugs, there are many immune-related adverse events that can affect the skin (pruritus and rash), gastrointestinal tract (colitis, sometimes severe), liver, pancreas (diabetes mellitus), pituitary gland (hypophysitis, hypothyroidism, etc.) and lung (ILD) [122]. While these new drugs are promising, a history of immune diseases or diseases requiring immunosuppressive therapy (such as corticosteroids) can preclude the use of such therapies and are exclusion criteria in all the above cited studies.

\section{Special populations: elderly and HIV-infected patients}

Elderly patients have long been excluded from clinical trials. However, in patients with a performance status of $0-2$, carboplatin and weekly paclitaxel doublet chemotherapy has been associated with survival benefits compared to those of monotherapy and is now the new paradigm of treatment for these patients [123]. Recommendations for treatment of advanced NSCLC are lacking in HIV+ patients, because HIV seropositivity is an exclusion criteria in most trials. The management of these patients is difficult, partly because of the aggressive nature of the tumour and partly because of comorbidities and potential interactions between anticancer and antiretroviral therapies. A recent study has evaluated the combination of the front-line chemotherapy carboplatin-pemetrexed followed by maintenance pemetrexed in HIV+ patients with advanced NSCLC. These agents do not interact with HAART. This regimen was well tolerated and should become the standard first-line chemotherapy regimen for HIV+ patients [124].

\section{Psychological and social factors}

Some psychological and social factors could influence the outcome of patients with lung cancer. Because these factors can impact the tolerance of the treatments, they influence the selection of lung cancer 
treatment. In a Norwegian study of 24324 lung cancer patients, the influence of income, education, age and place of residence on treatment was evaluated [125]. Surgery and radical and palliative radiotherapy were underused among the elderly and those with a lower socioeconomic status, which is of concern given the universal health coverage in this country. High-quality radiotherapy requires rigid immobilisation of patients and accurate positioning of their targets. For some tumour locations, especially for tumours located closed to the spinal cord, patients may need to wear a five-point mask covering the head, neck and shoulders to help them keep still. Wearing a mask can be a source of fears for some patients. Claustrophobic patients are unable to stay under a standard head mask throughout the treatment. One solution is to use an open-face hybrid mask which leaves the eyes, nose and mouth exposed [126, 127]. The mask is not in the field of view of the patient, which makes it much more comfortable. Hypnosis can also be useful in radiotherapy [128] and is an effective method to ease the simulation computed tomography scan and the first sessions of radiation therapy. Patients who benefit from hypnosis in the first and second sessions can then usually continue the treatment without hypnosis. It can be difficult for patients with dementia or psychosis to undergo radiation treatment. Besides the ethical aspects raised by the condition of such patients, they can find it difficult to keep still during the radiotherapy sessions and therefore can require premedication. The place of residence can also impact the choice of treatment. Indeed, a large distance between the patient's residence and the cancer centre could result in the patient being more tired because they have to travel every day, 5 days a week, for the radiation treatment; this can have a negative impact on the treatment outcome [129]. Finally, a lack of universal health coverage can impact chemotherapy use, especially in countries like the USA. In 2010 it was reported that only about $20 \%$ of patients in the USA aged $>65$ years received chemotherapy for advanced NSCLC and there was a correlation with income [130]. These US estimates contrast poorly with European estimates: in France, in 2010, a large majority of elderly patients with lung cancer were managed like their younger counterparts and only $16 \%$ of them had best supportive care as a unique treatment [131]. Even when health coverage is guaranteed, some psychosocial factors can play a role, such as the absence of a phone, mental disorders etc.

\section{Conclusion}

Contrary to other cancers, e.g. breast cancer, lung cancer often occurs in patients with comorbidities that can prevent the realisation of some diagnostic procedures and treatments. The high frequency of comorbidities is mainly due to a common risk factor, i.e. tobacco use, but also to the fact that the median age of patients with lung cancer is around 70 years, with the inherent development of CVDs, renal insufficiency, etc. that are related to an advanced age. In some situations, rehabilitation, i.e. the correction of metabolic disorders, can allow the appropriate treatment in most patients, including those who are frail.

\section{References}

1 de Torres JP, Marín JM, Casanova C, et al. Lung cancer in patients with chronic obstructive pulmonary disease--incidence and predicting factors. Am J Respir Crit Care Med 2011; 184: 913-919.

2 Young RP, Hopkins RJ, Christmas T, et al. COPD prevalence is increased in lung cancer, independent of age, sex and smoking history. Eur Respir J 2009; 34: 380-386.

3 Wasswa-Kintu S, Gan WQ, Man SFP, et al. Relationship between reduced forced expiratory volume in one second and the risk of lung cancer: a systematic review and meta-analysis. Thorax 2005; 60: 570-575.

4 Henschke CI, Yip R, Boffetta P, et al. CT screening for lung cancer: importance of emphysema for never smokers and smokers. Lung Cancer 2015; 88: 42-47.

5 Zhai R, Yu X, Shafer A, et al. The impact of coexisting COPD on survival of patients with early-stage non-small cell lung cancer undergoing surgical resection. Chest $J$ 2014; 145: 346-353.

6 Sunnetcioglu A, Alp HH, Sertogullarından B, et al. Evaluation of oxidative damage and antioxidant mechanisms in COPD, lung cancer, and obstructive sleep apnea syndrome. Respir Care 2016; 61: 205-211.

$7 \quad$ Vakkila J, Lotze MT. Inflammation and necrosis promote tumour growth. Nat Rev Immunol 2004; 4: 641-648.

8 Dixon K, Kopras E. Genetic alterations and DNA repair in human carcinogenesis. Semin Cancer Biol 2004; 14: 441-448.

9 Pillai SG, Ge D, Zhu G, et al. A genome-wide association study in chronic obstructive pulmonary disease (COPD): identification of two major susceptibility loci. PLoS Genet 2009; 5: e1000421.

10 Wauters E, Smeets D, Coolen J, et al. The TERT-CLPTM1L locus for lung cancer predisposes to bronchial obstruction and emphysema. Eur Respir J 2011; 38: 924-931.

11 Maltby S, Plank M, Tay HL, et al. Targeting MicroRNA function in respiratory diseases: mini-review. Respir Physiol 2016; 21.

12 Neves PC, Guerra M, Ponce P, et al. Non-cystic fibrosis bronchiectasis. Interact Cardiovasc Thorac Surg 2011; 13: 619-625.

13 Kuper H, Adami HO, Trichopoulos D. Infections as a major preventable cause of human cancer. J Intern Med 2000; 248: 171-183

14 Bobba RK, Holly JS, Loy T, et al. Scar carcinoma of the lung: a historical perspective. Clin Lung Cancer 2011; 12: $148-154$.

15 Chung W-S, Lin C-L, Lin C-L, et al. Bronchiectasis and the risk of cancer: a nationwide retrospective cohort study. Int J Clin Pract 2015; 69: 682-688.

16 Raviglione M, Sulis G. Tuberculosis 2015: burden, challenges and strategy for control and elimination. Infect Dis Rep 2016; 8: 6570 . 
17 Falzon D, Kudjawu YC, Desenclos JC, et al. Stopping TB in Europe: some progress but still not there Euro Surveill 2008; 13: ppii: 8073.

18 Coussens LM, Werb Z. Inflammation and cancer. Nature 2002; 420: 860-867.

19 Ballaz S, Mulshine JL. The potential contributions of chronic inflammation to lung carcinogenesis. Clin Lung Cancer 2003; 5: 46-62.

20 Shiels MS, Albanes D, Virtamo J, et al. Increased risk of lung cancer in men with tuberculosis in the alpha-tocopherol, beta-carotene cancer prevention study. Cancer Epidemiol Biomarkers Prev 2011; 20: 672-678.

21 Chen Y-M, Chao J-Y, Tsai C-M, et al. Shortened survival of lung cancer patients initially presenting with pulmonary tuberculosis. Jpn J Clin Oncol 1996; 26: 322-327.

22 Yu Y-H, Liao C-C, Hsu W-H, et al. Increased lung cancer risk among patients with pulmonary tuberculosis: a population cohort study. J Thorac Oncol 2011; 6: 32-37.

23 Liang H-Y, Li X-L, Yu X-S, et al. Facts and fiction of the relationship between preexisting tuberculosis and lung cancer risk: a systematic review. Int J Cancer 2009; 125: 2936-2944.

$24 \mathrm{Wu} \mathrm{C}-\mathrm{Y}, \mathrm{Hu} \mathrm{H}-\mathrm{Y}, \mathrm{Pu} \mathrm{C}-\mathrm{Y}$, et al. Pulmonary tuberculosis increases the risk of lung cancer: a population-based cohort study. Cancer 2011; 117: 618-624.

25 Heuvers ME, Aerts JGJV, Hegmans JP, et al. History of tuberculosis as an independent prognostic factor for lung cancer survival. Lung Cancer 2012; 76: 452-456.

26 Radisky DC, Kenny PA, Bissell MJ. Fibrosis and cancer: do myofibroblasts come also from epithelial cells via EMT? J Cell Biochem 2007; 101: 830-839.

27 Wellner U, Schubert J, Burk UC, et al. The EMT-activator ZEB1 promotes tumorigenicity by repressing stemness-inhibiting microRNAs. Nat Cell Biol 2009; 11: 1487-1495.

28 Hubbard R, Venn A, Lewis S, et al. Lung cancer and cryptogenic fibrosing alveolitis: a population-based cohort study. Am J Respir Crit Care Med 2000; 161: 5-8.

29 Harris JM, Johnston IDA, Rudd R, et al. Cryptogenic fibrosing alveolitis and lung cancer: the BTS study. Thorax 2010; 65: 70-76.

30 Le Jeune I, Gribbin J, West J, et al. The incidence of cancer in patients with idiopathic pulmonary fibrosis and sarcoidosis in the UK. Respir Med 2007; 101: 2534-2540.

31 Goto T, Maeshima A, Oyamada Y, et al. Idiopathic pulmonary fibrosis as a prognostic factor in non-small cell lung cancer. Int J Clin Oncol 2014; 19: 266-273.

32 Park J, Kim DS, Shim TS, et al. Lung cancer in patients with idiopathic pulmonary fibrosis. Eur Respir J 2001 17: 1216-1219.

33 Khan KA, Kennedy MP, Moore E, et al. Radiological characteristics, histological features and clinical outcomes of lung cancer patients with coexistent idiopathic pulmonary fibrosis. Lung 2015; 193: 71-77.

34 Daniels CE, Jett JR. Does interstitial lung disease predispose to lung cancer? Curr Opin Pulm Med 2005; 11: 431-437.

35 Janssen-Heijnen ML, Schipper RM, Razenberg PP, et al. Prevalence of co-morbidity in lung cancer patients and its relationship with treatment: a population-based study. Lung Cancer 1998; 21: 105-113.

36 Ambrogi V, Pompeo E, Elia S, et al. The impact of cardiovascular comorbidity on the outcome of surgery for stage I and II non-small-cell lung cancer1. Eur J Cardiothorac Surg 2003; 23: 811-817.

37 IL6R Genetics Consortium Emerging Risk Factors Collaboration, et al.. Interleukin-6 receptor pathways in coronary heart disease: a collaborative meta-analysis of 82 studies. Lancet 2012; 379: 1205-1213.

38 Libby P. Inflammation and cardiovascular disease mechanisms. Am J Clin Nutr 2006; 83: 456S-460S.

39 Hatlen P, Langhammer A, Carlsen SM, et al. Self-reported cardiovascular disease and the risk of lung cancer, the HUNT study. J Thorac Oncol 2014; 9: 940-946.

40 Kravchenko J, Berry M, Arbeev K, et al. Cardiovascular comorbidities and survival of lung cancer patients: Medicare data based analysis. Lung Cancer 2015; 88: 85-93.

41 Janssen-Heijnen MLG, van Erning FN, De Ruysscher DK, et al. Variation in causes of death in patients with non-small cell lung cancer according to stage and time since diagnosis. Ann Oncol 2015; 26: 902-907.

42 Guiguet M, Boué F, Cadranel J, et al. Effect of immunodeficiency, HIV viral load, and antiretroviral therapy on the risk of individual malignancies (FHDH-ANRS CO4): a prospective cohort study. Lancet Oncol 2009; 10: $1152-1159$.

43 Hleyhel M, Belot A, Bouvier A-M, et al. Trends in survival after cancer diagnosis among HIV-infected individuals between 1992 and 2009. Results from the FHDH-ANRS CO4 cohort. Int J Cancer 2015; 137: 2443-2453.

44 Lanoy E, Spano J-P, Bonnet F, et al. The spectrum of malignancies in HIV-infected patients in 2006 in France: the ONCOVIH study. Int J Cancer 2011; 129: 467-475.

45 Suneja G, Shiels MS, Melville SK, et al. Disparities in the treatment and outcomes of lung cancer among HIV-infected individuals. AIDS 2013; 27: 459-468.

46 Tron L, Lert F, Spire B, et al. Tobacco smoking in HIV-infected versus general population in France: heterogeneity across the various groups of people living with HIV. PloS One 2014; 9: e107451.

47 Lavolé A, Chouaï C, Baudrin L, et al. Effect of highly active antiretroviral therapy on survival of HIV infected patients with non-small-cell lung cancer. Lung Cancer Amst Neth 2009; 65: 345-350.

48 Makinson A, Tenon J-C, Eymard-Duvernay S, et al. Human immunodeficiency virus infection and non-small cell lung cancer: survival and toxicity of antineoplastic chemotherapy in a cohort study. J Thorac Oncol 2011; 6: 1022-1029.

49 Moltó J, Moran T, Sirera G, et al. Lung cancer in HIV-infected patients in the combination antiretroviral treatment era. Transl Lung Cancer Res 2015; 4: 678-688.

50 Peng J-W, Liu D-Y, Lin G-N, et al. Hepatitis B virus infection is associated with poor prognosis in patients with advanced non small cell lung cancer. Asian Pac J Cancer Prev 2015; 16: 5285-5288.

51 Lok AS, Liang RH, Chiu EK, et al. Reactivation of hepatitis B virus replication in patients receiving cytotoxic therapy. Report of a prospective study. Gastroenterology 1991; 100: 182-188.

52 Xunrong L, Yan AW, Liang R, et al. Hepatitis B virus (HBV) reactivation after cytotoxic or immunosuppressive therapy--pathogenesis and management. Rev Med Virol 2001; 11: 287-299.

53 Lin G-N, Peng J-W, Xiao J, et al. Hepatitis B virus reactivation in hepatitis B surface antigen seropositive patients with metastatic non-small cell lung cancer receiving cytotoxic chemotherapy: the efficacy of preemptive lamivudine and identification of risk factors. Med Oncol 2014; 31: 119. 
Bui N, Wong-Sefidan I. Reactivation of hepatitis B virus after withdrawal of erlotinib. Curr Oncol Tor Ont 2015; 22: 430-432.

Yeo W, Johnson PJ. Diagnosis, prevention and management of hepatitis B virus reactivation during anticancer therapy. Hepatology 2006; 43: 209-220.

Loomba R, Rowley A, Wesley R, et al. Systematic review: the effect of preventive lamivudine on hepatitis B reactivation during chemotherapy. Ann Intern Med 2008; 148: 519-528.

Gower E, Estes C, Blach S, et al. Global epidemiology and genotype distribution of the hepatitis $\mathrm{C}$ virus infection. J Hepatol 2014; 61: S45-S57.

Malaguarnera M, Gargante MP, Risino C, et al. Hepatitis C virus in elderly cancer patients. Eur J Intern Med 2006; 17: 325-329.

Fiorino S, Bacchi-Reggiani L, de Biase D, et al. Possible association between hepatitis C virus and malignancies different from hepatocellular carcinoma: a systematic review. World J Gastroenterol 2015; 21: 12896-12953.

Vento S, Cainelli F, Longhi MS. Reactivation of replication of hepatitis B and C viruses after immunosuppressive therapy: an unresolved issue. Lancet Oncol 2002; 3: 333-340.

de Pree C, Giostra E, Galetto A, et al. Hepatitis C virus acute exacerbation during chemotherapy and radiotherapy for oesophageal carcinoma. Ann Oncol 1994; 5: 861-862.

Melisko ME, Fox R, Venook A. Reactivation of hepatitis C virus after chemotherapy for colon cancer. Clin Oncol $R$ Coll Radiol G B 2004; 16: 204-205.

Kellum JA, Lameire N, Aspelin P, et al. Work group membership. Kidney Int 2012; 2: 1.

Launay-Vacher V, Chatelut E, Lichtman S, et al. Renal insufficiency in elderly cancer patients: Internationa Society of Geriatric Oncology clinical practice recommendations. Ann Oncol 2007; 18: 1314-1321.

Owonikoko TK, Ragin CC, Belani CP, et al. Lung cancer in elderly patients: an analysis of the surveillance, epidemiology, and end results database. J Clin Oncol 2007; 25: 5570-5577.

Islam KMM, Jiang X, Anggondowati T, et al. Comorbidity and survival in lung cancer patients. Cancer Epidemiol Biomarkers Prev 2015; 24: 1079-1085.

Wild S, Roglic G, Green A, et al. Global prevalence of diabetes: estimates for the year 2000 and projections for 2030. Diabetes Care 2004; 27: 1047-1053.

Sciacca L, Vigneri R, Tumminia A, et al. Clinical and molecular mechanisms favoring cancer initiation and progression in diabetic patients. Nutr Metab Cardiovasc Dis 2013; 23: 808-815.

Arcidiacono B, Iiritano S, Nocera A, et al. Insulin resistance and cancer risk: an overview of the pathogenetic mechanisms. Exp Diabetes Res 2012; 2012: 789174.

Noto H, Tsujimoto T, Sasazuki T, et al. Significantly increased risk of cancer in patients with diabetes mellitus: a systematic review and meta-analysis. Endocr Pract 2011; 17: 616-628.

Zeng G, Rui W, Grouse L. Diabetes mellitus increases postoperative mortality in non-small cell lung cancer. Thorac Cancer 2014; 5: 111.

Tseng C-H. Higher risk of mortality from lung cancer in Taiwanese people with diabetes. Diabetes Res Clin Pract 2013; 102: 193-201.

Falcoz PE, Conti M, Brouchet L, et al. The Thoracic Surgery Scoring System (Thoracoscore): risk model for in-hospital death in 15,183 patients requiring thoracic surgery. J Thorac Cardiovasc Surg 2007; 133: 325-332.

Powell HA, Tata LJ, Baldwin DR, et al. Early mortality after surgical resection for lung cancer: an analysis of the English National Lung cancer audit. Thorax 2013; 68: 826-834.

Kaw R, Chung F, Pasupuleti V, et al. Meta-analysis of the association between obstructive sleep apnoea and postoperative outcome. Br J Anaesth 2012; 109: 897-906.

Benzo R, Wigle D, Novotny P, et al. Preoperative pulmonary rehabilitation before lung cancer resection: results from two randomized studies. Lung Cancer 2011; 74: 441-445.

Lorut C, Lefebvre A, Planquette B, et al. Early postoperative prophylactic noninvasive ventilation after major lung resection in COPD patients: a randomized controlled trial. Intensive Care Med 2014; 40: 220-227. influence of nutritional status. Eur J Cardiothorac Surg 2014; 45: 652-659; discussion 659.

our GA, Shanks AM, Kheterpal S. Perioperative stroke and associated mortality after noncardiac, nonneurologic surgery. Anesthesiology 2011; 114: 1289-1296.

European Stroke O,Tendera M, Aboyans V, et al. ESC Guidelines on the diagnosis and treatment of peripheral artery diseases: Document covering atherosclerotic disease of extracranial carotid and vertebral, mesenteric, renal, upper and lower extremity arteries: the Task Force on the Diagnosis and Treatment of Peripheral Artery Diseases of the European Society of Cardiology (ESC). Eur Heart J 2011; 32: 2851-2906.

Lim E, Baldwin D, Beckles M, et al. Guidelines on the radical management of patients with lung cancer. Thorax 2010; 65: Suppl. 3, iiil-ii27.

Brunelli A, Charloux A, Bolliger CT, et al. ERS-ESTS clinical guidelines on fitness for radical therapy in lung cancer patients (surgery and radiochemotherapy). Eur Respir J 2009; 34: 17-41.

Brunelli A, Kim AW, Berger KI, et al. Physiologic evaluation of the patient with lung cancer being considered for resectional surgery: diagnosis and management of lung cancer, 3rd ed: American College of Chest Physicians evidence-based clinical practice guidelines. Chest 2013; 143: e166S-e190S.

Hammill BG, Curtis LH, Bennett-Guerrero E, et al. Impact of heart failure on patients undergoing major noncardiac surgery. Anesthesiology 2008; 108: 559-567.

Kazmers A, Cerqueira MD, Zierler RE. Perioperative and late outcome in patients with left ventricular ejection fraction of 35\% or less who require major vascular surgery. J Vasc Surg 1988; 8: 307-315.

Healy KO, Waksmonski CA, Altman RK, et al. Perioperative outcome and long-term mortality for heart failure patients undergoing intermediate- and high-risk noncardiac surgery: impact of left ventricular ejection fraction. Congest Heart Fail 2010; 16: 45-49.

Kristensen SD, Knuuti J, Saraste A, et al. 2014 ESC/ESA Guidelines on non-cardiac surgery: cardiovascular assessment and management: The Joint Task Force on non-cardiac surgery: cardiovascular assessment and management of the European Society of Cardiology (ESC) and the European Society of Anaesthesiology (ESA). Eur Heart J 2014; 35: 2383-2431.

Seppenwoolde Y, Lebesque JV. Partial irradiation of the lung. Semin Radiat Oncol 2001; 11: 247-258. 

parameters in lung cancer--a systematic review. Radiother Oncol 2004; 71: 127-138.

90 Seppenwoolde Y, Lebesque JV, de Jaeger K, et al. Comparing different NTCP models that predict the incidence of radiation pneumonitis. Normal tissue complication probability. Int J Radiat Oncol Biol Phys 2003; 55: 724-735.

91 Brooks BJ Jr, Seifter EJ, Walsh TE, et al. Pulmonary toxicity with combined modality therapy for limited stage small-cell lung cancer. J Clin Oncol 1986; 4: 200-209.

92 Yamada M, Kudoh S, Hirata K, et al. Risk factors of pneumonitis following chemoradiotherapy for lung cancer. Eur J Cancer 1998; 34: 71-75.

93 Lee JS, Scott C, Komaki R Jr, et al. Concurrent chemoradiation therapy with oral etoposide and cisplatin for locally advanced inoperable non-small-cell lung cancer: radiation therapy oncology group protocol 91-06. $J$ Clin Oncol 1996; 14: 1055-1064.

94 Byhardt RW, Scott C, Sause WT, et al. Response, toxicity, failure patterns, and survival in five Radiation Therapy Oncology Group (RTOG) trials of sequential and/or concurrent chemotherapy and radiotherapy for locally advanced non-small-cell carcinoma of the lung. Int J Radiat Oncol Biol Phys 1998; 42: 469-478.

95 Robert F, Childs HA, Spencer SA, et al. Phase I/IIa study of concurrent paclitaxel and cisplatin with radiation therapy in locally advanced non-small cell lung cancer: analysis of early and late pulmonary morbidity. Semin Radiat Oncol 1999; 9: 136-147.

96 Monson JM, Stark P, Reilly JJ, et al. Clinical radiation pneumonitis and radiographic changes after thoracic radiation therapy for lung carcinoma. Cancer 1998; 82: 842-850.

97 Robnett TJ, Machtay M, Vines EF, et al. Factors predicting severe radiation pneumonitis in patients receiving definitive chemoradiation for lung cancer. Int J Radiat Oncol Biol Phys 2000; 48: 89-94.

98 Rancati T, Ceresoli GL, Gagliardi G, et al. Factors predicting radiation pneumonitis in lung cancer patients: a retrospective study. Radiother Oncol 2003; 67: 275-283.

99 Claude L, Perol D, Ginestet C, et al. A prospective study on radiation pneumonitis following conformal radiation therapy in non-small-cell lung cancer: clinical and dosimetric factors analysis. Radiother Oncol 2004; 71: 175-181.

100 Jeremic B, Shibamoto Y, Acimovic L, et al. Hyperfractionated radiation therapy with or without concurrent low-dose daily carboplatin/etoposide for stage III non-small-cell lung cancer: a randomized study. J Clin Oncol 1996; 14: 1065-1070.

101 Quon H, Shepherd FA, Payne DG, et al. The influence of age on the delivery, tolerance, and efficacy of thoracic irradiation in the combined modality treatment of limited stage small cell lung cancer. Int J Radiat Oncol Biol Phys 1999; 43: 39-45.

102 Hernando ML, Marks LB, Bentel GC, et al. Radiation-induced pulmonary toxicity: a dose-volume histogram analysis in 201 patients with lung cancer. Int J Radiat Oncol Biol Phys 2001; 51: 650-659.

103 Yamaguchi S, Ohguri T, Matsuki Y, et al. Radiotherapy for thoracic tumors: association between subclinical interstitial lung disease and fatal radiation pneumonitis. Int J Clin Oncol 2015; 20: 45-52.

104 Schaake-Koning C, van den Bogaert W, Dalesio O, et al. Effects of concomitant cisplatin and radiotherapy on inoperable non-small-cell lung cancer. N Engl J Med 1992; 326: 524-530.

105 Sculier JP, Botta I, Bucalau AM, et al. Medical anticancer treatment of lung cancer associated with comorbidities a review. Lung Cancer 2015; 87: 241-248.

106 Pai VB, Nahata MC. Cardiotoxicity of chemotherapeutic agents: incidence, treatment and prevention. Drug Saf 2000; 22: 263-302.

107 Lichtman SM, Wildiers H, Launay-Vacher V, et al. International Society of Geriatric Oncology (SIOG) recommendations for the adjustment of dosing in elderly cancer patients with renal insufficiency. Eur $J$ Cancer 2007; 43: 14-34.

108 Kuo JC, Craft PS. Administration of chemotherapy in patients on dialysis. Anticancer Drugs 2015; 26: 779-784.

109 Isobe K, Hata Y, Sakamoto S, et al. Clinical characteristics of acute respiratory deterioration in pulmonary fibrosis associated with lung cancer following anti-cancer therapy. Respirology 2010; 15: 88-92.

110 Minegishi Y, Takenaka K, Mizutani H, et al. Exacerbation of idiopathic interstitial pneumonias associated with lung cancer therapy. Intern Med Tokyo Jpn 2009; 48: 665-672.

111 Pavlakis N, Bell DR, Millward MJ, et al. Fatal pulmonary toxicity resulting from treatment with gemcitabine. Cancer 1997; 80: 286-291.

112 Read WL, Mortimer JE, Picus J. Severe interstitial pneumonitis associated with docetaxel administration. Cancer 2002; 94: 847-853.

113 Okuda K, Hirose T, Oki Y, et al. Evaluation of the safety and efficacy of combination chemotherapy with vinorelbine and platinum agents for patients with non-small cell lung cancer with interstitial lung disease. Anticancer Res 2012; 32: 5475-5480.

114 Créquit P, Wislez M, Fleury Feith J, et al. Crizotinib associated with ground-glass opacity predominant pattern interstitial lung disease: a retrospective observational cohort study with a systematic literature review. J Thorac Oncol 2015; 10: 1148-1155.

115 Naito Y, Tsuchiya S, Ishihara S, et al. Impact of preexisting pulmonary fibrosis detected on chest radiograph and CT on the development of gefitinib-related interstitial lung disease. Am J Clin Oncol 2008; 31: 340-344.

116 Rossi A, Maione P, Gaizo FD, et al. Safety profile of gefitinib in advanced non-small cell lung cancer elderly patients with chronic renal failure: two clinical cases. Lung Cancer 2005; 47: 421-423.

117 Togashi Y, Masago K, Fukudo M, et al. Pharmacokinetics of erlotinib and its active metabolite OSI-420 in patients with non-small cell lung cancer and chronic renal failure who are undergoing hemodialysis. $J$ Thorac Oncol 2010; 5: 601-605.

118 Brahmer J, Reckamp KL, Baas P, et al. Nivolumab versus docetaxel in advanced squamous-cell non-small-cell lung cancer. N Engl J Med 2015; 373: 123-135.

119 Borghaei H, Paz-Ares L, Horn L, et al. Nivolumab versus docetaxel in advanced nonsquamous non-small-cell lung cancer. N Engl J Med 2015; 373: 1627-1639.

120 Herbst RS, Baas P, Kim D-W, et al. Pembrolizumab versus docetaxel for previously treated, PD-L1-positive, advanced non-small-cell lung cancer (KEYNOTE-010): a randomised controlled trial. Lancet 2016; 387: $1540-1550$ 
121 Reck M, Rodríguez-Abreu D, Robinson AG, et al. Pembrolizumab versus chemotherapy for PD-L1-positive non-small-cell lung cancer. N Engl J Med 2016; 375: 1823-1833.

122 Howell M, Lee R, Bowyer S, et al. Optimal management of immune-related toxicities associated with checkpoint inhibitors in lung cancer. Lung Cancer Amst Neth 2015; 88: 117-123.

123 Quoix E, Zalcman G, Oster J-P, et al. Carboplatin and weekly paclitaxel doublet chemotherapy compared with monotherapy in elderly patients with advanced non-small-cell lung cancer: IFCT-0501 randomised, phase 3 trial. Lancet 2011; 378: 1079-1088.

124 Lavolé A, Tomasini P, Monnet I, et al. IFCT-1001 CHIVA trial: a phase II study of carboplatin (Ca) plus pemetrexed (P) followed by $\mathrm{P}$ maintenance, as first-line therapy for human immunodeficiency virus (HIV)associated advanced non-squamous non-small cell lung cancer (NS-NSCLC). J Clin Oncol 2016; 34: Suppl., 9076.

125 Nilssen Y, Strand TE, Fjellbirkeland L, et al. Lung cancer treatment is influenced by income, education, age and place of residence in a country with universal health coverage. Int J Cancer 2016; 138: 1350-1360.

126 Ju H, Kim S, Read P, et al. Development of a novel remote-controlled and self-contained audiovisual-aided interactive system for immobilizing claustrophobic patients. J Appl Clin Med Phys 2015; 16: 5359.

127 Li G, Lovelock DM, Mechalakos J, et al. Migration from full-head mask to "open-face" mask for immobilization of patients with head and neck cancer. J Appl Clin Med Phys 2013; 14: 243-254.

128 Néron S, Stephenson R. Effectiveness of hypnotherapy with cancer patients' trajectory: emesis, acute pain, and analgesia and anxiolysis in procedures. Int J Clin Exp Hypn 2007; 55: 336-354.

129 Wheeler SB, Kuo T-M, Durham D, et al. Effects of distance to care and rural or urban residence on receipt of radiation therapy among North Carolina Medicare enrollees with breast cancer. N C Med J 2014; 75: 239-246.

130 Davidoff AJ, Tang M, Seal B, et al. Chemotherapy and survival benefit in elderly patients with advanced non-small-cell lung cancer. J Clin Oncol 2010; 28: 2191-2197.

131 Quoix E, Monnet I, Scheid P, et al. [Management and outcome of French elderly patients with lung cancer: an IFCT survey]. Rev Mal Respir 2010; 27: 421-430. 